\title{
autêntica
}

ARTIGOS

\section{PNE 2014-2024 E AS POLÍTICAS DE FORMAÇÃO DO PROFESSOR DA EDUCAÇÃO INFANTIL: CONQUISTAS E TENSÕES}

Denise de Barros Capuzzo

Denise Silva Araújo

RESUMO: No artigo, analisam-se as metas do PNE (2014-2024), que impactam a formação de professores da educação infantil. Inicialmente, discute-se a Meta 1, que trata da educação da criança pequena para compreender aquelas que se referem aos docentes que nela atuam. Para expandir e melhorar a qualidade do atendimento das crianças de 0 a 5 anos, é necessário o esforço articulado do poder público nas três esferas. A universalização da pré-escola deve permitir a superação das desigualdades de atendimento e não pode significar a redução da oferta de vagas para as crianças de 0 a 3 anos. Para tanto, são imprescindíveis políticas de formação inicial e continuada e de valorização dos profissionais que atuam na primeira etapa da educação básica. Essa questão foi abordada nas Metas 15, 16, 17 e 18. Defende-se que os docentes da Educação Infantil, assim como os professores de todos os níveis, etapas e modalidades da educação nacional, tenham assegurada sua formação inicial e continuada, articuladamente a salários dignos, a plano de carreira e ao reconhecimento profissional, para possibilitar a qualidade social da educação da criança pequena.

PALAVRAS CHAVE: PNE; Políticas educacionais; Formação docente; Educação infantil

\begin{abstract}
In the article, we analyze the goals of the PNE (2014-2024), that impact the formation of teachers that work with early childhood education. Initially, we discussed the Goal 01 which treats of the small child's education to understand the goals that mention the teachers who work in it. To expand and improve the quality of care and education of children from 0 to 5 years old is required concerted effort of the government at all three levels. The universal pre-school should enable the overcoming of the inequalities and it cannot means reducing the number of places for children 0-3 years. To this end, initial and continuing education policies and valuation of the professionals who work with young children are essential. This subject was treated in the Goals 15, 16, 17 and 18. We advocate that teachers of early childhood education, as well as teachers of all levels, stages and modalities of national education, should be assured their initial and continuing education articulated to fair wages, career path and professional recognition and acceptance, to enable the social quality of the small child's education.
\end{abstract}

KEYWORDS: PNE; Educational policy; Teacher education; Early childhood education 


\section{autêntica}

\section{INTRODUÇÃO}

Neste artigo, objetiva-se analisar as metas do Plano Nacional de Educação (PNE 2014-2024) referentes às políticas de formação de professores para a educação infantil. Para tanto, é importante situá-las no contexto das políticas públicas para o atendimento à criança pequena e para a formação de professores, a fim de se analisarem as possibilidades e os desafios a serem enfrentados nos próximos dez anos no que se refere à formação dos docentes que atuam na primeira etapa da educação básica.

Por força da Emenda Constitucional n 59, de 2009 (BRASIL, 2009a), a condição do PNE passou de uma disposição transitória da Lei de Diretrizes e Bases da Educação Nacional - Lei nº 9.394/1996 (BRASIL, 1996) - para uma exigência constitucional com periodicidade decenal. A partir daí, o PNE constitui-se como balizador das políticas educacionais que devem ser referência para os planos plurianuais e para os planos estaduais, distrital e municipais. Além disso, também passou a ser compreendido como o articulador do Sistema Nacional de Educação.

Depois de tramitar por três anos e meio, o PNE 2014-2024 foi aprovado pelo Congresso Nacional, por meio da Lei $n^{\circ}$ 13.005/2014 (BRASIL, 2014a), e sancionado sem vetos pela presidenta Dilma Rousseff, em 25 de junho de 2014. É importante afirmar que essa foi uma conquista dos movimentos sociais. Por intermédio de diversas entidades nacionais que defendem a educação pública como direito de todos os cidadãos desde o nascimento, a sociedade civil esteve articulada e assumiu um papel de protagonista na construção e na aprovação desse PNE, que terá a vigência no período de 2014 a 2024. Essa articulação ocorreu durante todo o processo de tramitação do PNE 2014-2024 e mesmo antes da elaboração do Projeto de Lei n 8.035/2010 (BRASIL, 2010), enviado pelo Poder Executivo ao Congresso Nacional, em dezembro de 2010.

Essa participação foi evidenciada, principalmente, no processo de preparação e de realização das Conferências Nacionais de Educação (CONAE/2010 e CONAE/2014), nos âmbitos intermunicipais, estaduais e nacional. Como decorrência dessa mobilização, vale destacar a conquista da previsão do percentual do Produto Interno Bruto (PIB) para o financiamento da educação e da exigência que, da mesma forma, os planos estaduais, distrital e municipais, também, prevejam recursos orçamentários para a sua execução e sejam aprovados na forma de leis.

O PNE está organizado a partir de dez diretrizes gerais e vinte metas, que se desdobram em estratégias, as quais apontam as políticas necessárias para efetivar as metas estabelecidas. Para analisá-las, é importante situá-las no contexto legal mais amplo em que se inserem, compreendendo, principalmente, as alterações que foram promovidas na Constituição Federal - CF/1988 (BRASIL, 1988) - e na Lei de Diretrizes e Bases da Educação Nacional - Lei n 9.394/1996 (BRASIL, 1996) -, visto que muitas dessas metas estão intimamente ligadas ao que ficou determinado nessa legislação e a questões pendentes que necessitam de regulamentação.

Assegurar direitos ou estabelecer determinada meta, no texto da lei, não é garantia de sua efetivação na realidade educacional, entretanto representa um passo importante na luta pela conquista dos direitos sociais de todos os cidadãos, visto que fornece instrumentos concretos para a cobrança desses direitos e, desse modo, fortalece e empodera a população. Daí a importância de nos debruçarmos na compreensão das metas estabelecidas no PNE 2014-2024, a fim de apreendermos o que elas apresentam como conquistas e como desafios a serem enfrentados. Neste texto, enfatizaremos aquelas que impactam mais diretamente a formação de professores que trabalham com as crianças de zero a cinco anos. Inicialmente, porém, analisaremos as metas relacionadas com a educação infantil, para, nesse contexto, compreendermos aquelas que tratam dos docentes que nela atuam. 


\section{autêntica}

\section{A META 1 E A UNIVERSALIZAÇÃO DA PRÉ-ESCOLA: CONQUISTA OU PERDA DE DIREITOS PARA AS CRIANÇAS PEQUENAS?}

A Meta 1 do PNE 2014-2024 trata especificamente da educação infantil e, por isso, será mais detidamente analisada neste item do artigo. No novo PNE (BRASIL, 2014a) ficou estabelecida a mesma meta prescrita no PNE 2001-2010 para a creche: matricular 50\% da população na faixa etária compreendida entre zero a três anos até o final da década (BRASIL, 2001).

Ganzeli (2012) avalia que, ao repetir a meta do plano anterior, o atual PNE ignorou as conquistas efetivadas, no período de dez anos. A autora reconhece que as estatísticas evidenciam um avanço vagaroso das matrículas em creches, em todo o território nacional. Apesar disso, ela defende que as metas deveriam indicar a vontade política de empreender uma mudança nessa realidade e fixar um período para sua efetivação.

Com a Meta 1, o PNE 2014-2024 evidencia uma intenção restrita no que se refere à ampliação da oferta de matrículas em creche. Isso nos fornece indicativos das intenções do poder público no que tange à educação das crianças de zero a três anos de idade: ela não consiste em uma prioridade a ser vencida na vigência desse Plano.

Por outro lado, no que se refere à educação das crianças de quatro a cinco anos, a meta determina sua universalização até 2016 (BRASIL, 2014a), acompanhando o que dispõe a Emenda no 59 de 2009 (BRASIL, 2009a), já mencionada neste artigo, que dá nova redação aos incisos I e VII do art. 208, da Constituição Federal - CF/1988 (BRASIL, 1988) -, para instituir a obrigatoriedade do ensino na faixa etária de quatro a dezessete anos. Com esse dispositivo legal, a pré-escola tornou-se uma etapa obrigatória e direito público subjetivo regulamentado pela Lei no 12.796/2013 (BRASIL, 2013). Essa obrigatoriedade deve ser implementada, progressivamente, até 2016, nos termos do PNE 2014-2024, com apoio técnico e financeiro da União.

Essa emenda constitucional pode ser considerada um marco na educação brasileira, porque visa propiciar a universalização e a democratização do acesso à pré-escola e ao ensino médio. Como uma das formas de viabilizá-la, expande a cobertura dos programas suplementares (merenda escolar, material didático-escolar e livros de literatura, transporte escolar e assistência à saúde), anteriormente restrita ao ensino fundamental, para os alunos de todas as etapas da educação básica.

Além disso, como resultado de sérios embates promovidos pelos movimentos sociais, a emenda determina o fim do percentual da Desvinculação das Receitas da União (DRU), incidente sobre os recursos públicos destinados à manutenção e ao desenvolvimento do ensino de que trata o art. 212 da Constituição Federal, a partir de 2011. Com isso, ampliam-se os recursos financeiros aplicados na educação. Outro ganho dessa medida foi a indicação que o novo PNE deveria estabelecer uma meta de aplicação de recursos públicos, no setor, como proporção do Produto Interno Bruto (PIB).

De acordo com Araújo; Silveira; Cotrim (2013), a obrigatoriedade da matrícula da criança de quatro e cinco anos na pré-escola provocou reações diversas dos profissionais e estudiosos da educação infantil e dos dirigentes da educação, pois a desejada universalização da pré-escola não deve ser alcançada com a imposição da matrícula à família, mas com a ampliação da oferta, a fim de atender à demanda reprimida durante décadas por falta de vagas.

Os dirigentes da educação municipal e federal destacam como pontos positivos da medida aprovada o fato de que ela permite a demanda organizada das famílias e assegura recursos financeiros para sua implantação. Ademais, a universalização da pré-escola é considerada como uma das medidas que têm alto potencial de produzir impactos positivos no ensino fundamental. 


\section{autêntica}

Os estudiosos e militantes da educação infantil apresentam vários argumentos contrários a essa medida constitucional, que pode induzir a uma expansão quantitativa da pré-escola sem assegurar sua qualidade social: o risco da diminuição da sua oferta do atendimento em período integral e da exclusão da dimensão do cuidado desta fase da educação infantil; a antecipação da escolaridade com as características do ensino fundamental; a fragmentação provocada no interior da educação infantil, com a cisão das duas fases, creche e pré-escola; a privatização da creche em razão do seu abandono pelo poder público (ARAÚJO; SILVEIRA; COTRIM, 2013).

No que se refere à possibilidade real de implantação desse dispositivo constitucional e do alcance da Meta 1 do PNE 2014-2024, as estatísticas evidenciam a proximidade com a universalização da pré-escola, pois o percentual de crianças, na idade de 4 a 6 anos, que frequentavam instituições educativas, em 2008, alcançou a média nacional de 80\%, atingindo, antecipadamente, a meta prevista para 2010, no PNE 2001-2010. Dados do Instituto Brasileiro de Geografia e Estatística (IBGE) mostram que, no ano de 2013, a cobertura na pré-escola atingiu o índice de 95,2\% (BRASIL, 2014 b).

Vieira (2010) afirma, porém, com base nos resultados da Pesquisa Nacional por Amostra a Domicílios (Pnad), que a frequência das crianças de zero a cinco anos em instituições educativas evidenciou desigualdades significativas, segundo as faixas de renda das famílias, a etnia/cor, a localização (urbano/rural) e a escolaridade dos pais/responsáveis, sobretudo da mãe. Além desses aspectos, a autora enfatiza a necessidade de superar as diferenças no acesso observadas entre as regiões e entes federados, que vêm sendo insistentemente apontadas nos estudos sobre a oferta de educação infantil no Brasil. As estatísticas evidenciam que as crianças menores, as provenientes de famílias de menor renda e as não brancas constituem o grupo daquelas mais prejudicadas.

A autora alega que, desde o início deste século, o atendimento de crianças de 4 a 6 anos, oriundas de famílias com rendimento familiar acima de três salários mínimos, está perto da universalização. Para demonstrar esse fato, a autora cita os seguintes indicadores: em 2004, 94,3\% de crianças de 4 a 6 anos de famílias de renda superior frequentavam a pré-escola e, em 2008, esse índice alcançou o valor de 98,8\%.

Por outro lado, as crianças de quatro a cinco anos oriundas de famílias com renda inferior atingiram, em 2004, uma porcentagem de frequência de $63,2 \%$, ou seja, bem abaixo da meta de $80 \%$. Em 2008, essa frequência aproximou-se da meta, pois alcançou uma cobertura de $77,1 \%$.

Vieira (2010) destaca, ainda, as desigualdades no atendimento às crianças dessa faixa etária entre as que vivem no campo e na cidade: em 2008, 80,4\% das crianças que residiam em área urbana foram atendidas, enquanto que, na área rural, apenas $66 \%$.

Esses números demonstram que, apesar de persistirem as desigualdades de acesso, é bastante atingível a meta de universalização do atendimento para essa faixa etária até 2016. Vale perguntar em que condições de oferta e a que preço, no que se refere à qualidade do atendimento das crianças de quatro e cinco anos e no abandono das menores por parte do poder público?

Mesmo antes de 2016, prazo estabelecido para a implantação da medida, vários dos receios enunciados já têm se concretizado e a expansão da pré-escola tem se efetivado pela via mais rápida e barata: 1) a criação ou a adaptação precária de salas de crianças de quatro e de cinco anos, nas escolas de ensino fundamental, que não possuem condições materiais e humanas para absorvê-las, respeitando suas necessidades 


\section{autêntica}

e especificidades, como determinam as diretrizes curriculares para a educação infantil; e 2) a criação de escolas de educação infantil (EMEIs), destinadas apenas à faixa etária obrigatória, com o atendimento em período parcial.

O que se evidencia é uma concepção fragmentada da educação infantil, que remonta a suas origens históricas, identificando a creche com instituições filantrópicas destinadas a atender crianças oriundas de famílias de baixa renda, a fim de liberar os pais para o trabalho. A pré-escola, por sua vez, é valorizada como forma de preparar a criança para o ensino fundamental potencializando suas chances de sucesso escolar. Ignoram-se, assim, as conquistas dos movimentos sociais que, na Constituição Federal de 1988 e na Lei de Diretrizes e Bases da Educação Nacional de 1996, unificaram as duas fases em uma única etapa da educação básica, articulada por um objetivo comum: promover o desenvolvimento integral das crianças, consideradas como sujeitos de direitos, de sua história, de sua cultura, de seu desenvolvimento e aprendizagem.

É importante enfatizar que a universalização da pré-escola deve permitir a superação das desigualdades de atendimento mencionadas anteriormente, ou seja, alcançar as crianças dos meios populares das cidades e do campo, incluindo as indígenas e quilombolas, as de famílias ribeirinhas e itinerantes. A estratégia 1.10 visa promover especificamente a superação dessas desigualdades, respeitando suas necessidades e especificidades:

1.10) fomentar o atendimento das populações do campo e das comunidades indígenas e quilombolas na educação infantil, por meio do redimensionamento da distribuição territorial da oferta, limitando a nucleação de escolas e o deslocamento das crianças, de forma a atender às especificidades dessas comunidades, garantida consulta prévia e informada (BRASIL, 2014a).

Além disso, para que seja realmente universalizado, o atendimento educacional da criança de quatro a cinco anos deve envolver aquelas que possuem deficiência, transtorno no seu desenvolvimento ou altas habilidades/ superdotação. A estratégia 1.11 trata especificamente da universalização da educação infantil para essa população, sem distinguir as faixas etárias e assegurando o atendimento educacional especializado a que têm direito, como se lê:

1.11) fomentar o acesso à educação infantil e a oferta do atendimento educacional especializado complementar e suplementar aos/às alunos/as com deficiência, transtornos globais do desenvolvimento e altas habilidades ou superdotação, assegurando a educação bilíngue para crianças surdas e a transversalidade da educação especial nessa etapa da educação básica (BRASIL, 2014a).

A Meta 4, por sua vez, aborda, especificamente, no seu conjunto, uma série de estratégias para que a universalização do ensino na faixa etária de quatro a dezessete anos inclua as crianças e adolescentes com alguma deficiência, transtorno no desenvolvimento, altas habilidades ou superdotação, da seguinte maneira:

Meta 4: universalizar, para a população de quatro a dezessete anos com deficiência, transtornos globais do desenvolvimento e altas habilidades ou superdotação, o acesso à educação básica e ao atendimento educacional especializado, preferencialmente na rede regular de ensino, com a garantia de sistema educacional inclusivo, de salas de recursos multifuncionais, classes, escolas ou serviços especializados, públicos ou conveniados (BRASIL, 2014a).

Vale destacar que incluir a criança com deficiência, transtorno no desenvolvimento, altas habilidades ou superdotação não significa apenas inseri-la nas instituições educativas regulares e extinguir as escolas 
especiais, mas oferecer condições objetivas, materiais e humanas, para que ela possa realmente aprender e se desenvolver. Isso implica desde adaptações arquitetônicas até curriculares, além da formação dos profissionais da educação que com ela atuam. A implantação dos núcleos de atendimento especializados e a formação de equipes de apoio interdisciplinares, também, são fundamentais, bem como a observância de todas as demais estratégias aprovadas na Meta 4.

É importante frisar que a obrigatoriedade escolar estendida à pré-escola não deve representar uma imposição às famílias, mas se transformar em conquista de experiências enriquecedoras e emancipadoras no percurso escolar de todas as crianças brasileiras, na faixa etária de quatro e cinco anos (VIEIRA, 2011). Além disso, essa conquista não pode significar a redução da oferta de vagas para as crianças de zero a três anos, que estão fora da faixa etária obrigatória e que vêm sendo mais penalizadas historicamente, no Brasil, tanto no que se refere aos aspectos quantitativos, quanto aos modelos de atendimento.

Uma das estratégias da Meta 4contribui nesse sentido, extrapolando a idade da escolarização obrigatória e prevendo a universalização do atendimento da demanda manifesta para o atendimento das crianças de zero a três anos com deficiência, transtorno no desenvolvimento, altas habilidades ou superdotação, como se evidencia:

4.2. promover, no prazo de vigência deste PNE, a universalização do atendimento escolar à demanda manifesta pelas famílias de crianças de zero a três anos com deficiência, transtornos globais do desenvolvimento e altas habilidades ou superdotação, observado o que dispõe a Lei n 9.394, de 20 de dezembro de 1996, que estabelece as diretrizes e bases da educação nacional (BRASIL, 2014a).

O grande desafio das políticas públicas empreendidas pelos municípios brasileiros atualmente é investir fortemente na educação infantil, conferindo centralidade no atendimento das crianças de 0 a 5 anos, 0 que demanda um esforço articulado do poder público nas três esferas, a fim de quitar a dívida que vem se acumulando historicamente no que se refere à educação das crianças pequenas, no país. Dados do IBGE evidenciam que, no ano de 2013, apesar do crescimento numérico das matrículas, o atendimento em creches atingiu menos de 30\% das crianças (BRASIL, 2014b).

Além da baixa cobertura do atendimento, nessa faixa etária, Vieira (2011), referendada pelos dados da Pesquisa Nacional por Amostra a Domicílios (Pnad), destacou a desigualdade de acesso às creches em relação à variável renda, que demonstrou ser ainda mais grave do que na pré-escola. Fundamentada em estudo do Instituto com relação ao ano de 2010, a autora demonstrou, por exemplo, que, do total das crianças atendidas nas creches, 36,3\% faziam parte dos $20 \%$ mais ricos da população e apenas 12,2\% integravam o estrato dos 20\% mais pobres. Em 2008, a frequência em creches de crianças oriundas de famílias com renda per capita de até meio salário mínimo (12,4\%) foi 3,2 vezes inferior à taxa de crianças de famílias com rendimento de três ou mais salários mínimos mensais (39,5\%).

Vieira (2010) registra as desigualdades de acesso à creche, no que se refere à cor/etnia, pois as crianças negras apresentaram, no ano de 2008, uma cobertura de 15,5\%, ao passo que as não negras ultrapassaram o percentual de $22 \%$. A autora denuncia, ainda, as desigualdades de atendimento das crianças bem pequenas no campo, pois apenas 6,4\% das crianças entre 0 e 3 anos foram atendidas, enquanto na área urbana, 19,6\% estavam na creche (IBGE, 2008, citado por VIEIRA, 2010).

É nesse contexto que deve ser compreendida a estratégia 1.2 do PNE 2014-2024, que almeja corrigir essas desigualdades e ampliar o atendimento à demanda para a faixa etária de zero a três anos, até então, mais prejudicada nas políticas públicas: 


\section{autêntica}

1.2) garantir que, ao final da vigência deste PNE, seja inferior a $10 \%$ (dez por cento) a diferença entre as taxas de frequência à educação infantil das crianças de até 3 (três) anos oriundas do quinto de renda familiar per capita mais elevado e a do quinto de renda familiar per capita mais baixo (BRASIL, 2014a).

A Meta 1 do novo PNE apresenta importantes estratégias, que visam contribuir com a ampliação quantitativa da cobertura da demanda na educação infantil, como um todo (zero a cinco anos), preservando, porém, o direito de opção da família de crianças de zero a três anos:

1.3) realizar, periodicamente, em regime de colaboração, levantamento da demanda por creche para a população de até 3 (três) anos, como forma de planejar a oferta e verificar o atendimento da demanda manifesta;

1.4) estabelecer, no $1^{\circ}$ (primeiro) ano de vigência do PNE, normas, procedimentos e prazos para definição de mecanismos de consulta pública da demanda das famílias por creches;

1.15) promover a busca ativa de crianças em idade correspondente à educação infantil, em parceria com órgãos públicos de assistência social, saúde e proteção à infância, preservando o direito de opção da família em relação às crianças de até 3 (três) anos;

1.16) o Distrito Federal e os Municípios, com a colaboração da União e dos Estados, realizarão e publicarão, a cada ano, levantamento da demanda manifesta por educação infantil em creches e pré-escolas, como forma de planejar e verificar o atendimento (BRASIL, 2014a).

Conhecer a demanda é fundamental para organizar a ampliação qualificada do acesso à educação infantil. Outras estratégias se referem a medidas necessárias para assegurar a qualidade do atendimento, como as de número: 1.6, 1.13, 1.17:

1.6) implantar, até o $2^{\circ}$ (segundo) ano da vigência deste PNE, avaliação da educação infantil, a ser realizada a cada 2 (dois) anos, com base em parâmetros nacionais de qualidade, a fim de aferir a infraestrutura física, o quadro de pessoal, as condições de gestão, os recursos pedagógicos, a situação de acessibilidade, entre outros indicadores relevantes;

1.13) preservar as especificidades da educação infantil na organização das redes escolares, garantindo o atendimento da criança de até 5 (cinco) anos em estabelecimentos que atendam a parâmetros nacionais de qualidade, e a articulação com a etapa escolar seguinte, visando ao ingresso do/a aluno/a de 6 (seis) anos de idade no ensino fundamental;

1.17) estimular o acesso à educação infantil em tempo integral para todas as crianças de até 5 (cinco) anos, conforme estabelecido nas Diretrizes Curriculares Nacionais para a Educação Infantil (BRASIL, 2014a).

Essas estratégias visam assegurar condições para a melhoria da qualidade do atendimento da educação infantil, mantendo padrões mínimos de qualidade, que devem orientar a avaliação dessa etapa da educação básica. Vale ressaltar a necessidade de se evitar repetir, na educação das crianças pequenas, os equívocos do ensino fundamental, médio e superior, de utilizar a avaliação das instituições e dos sistemas de ensino como uma forma de regulação em vez de indutora de políticas promotoras da qualidade social da educação. 


\section{autêntica}

Uma das lutas fundamentais, hoje, é preservar a compreensão da educação infantil como uma única etapa da educação básica, com especificidades que precisam ser respeitadas, evitando a fragmentação entre a creche e a pré-escola. Vieira (2011, p. 247) chama atenção para duas questões especialmente desafiantes na implantação desse PNE, no que se refere à educação infantil:

evitar a cisão da creche e da pré-escola, sob o risco de flexibilizar o significado da creche como 'atenção integral ao desenvolvimento da primeira infância', abrindo a possibilidade de alternativas de atendimento não formais, em espaços domésticos ou não, inadequados aos critérios educacionais, com pessoas sem formação e qualificação; e evitar o ingresso precoce de crianças na pré-escola e no ensino fundamental nos sistemas e redes de ensino.

Essa concepção de educação infantil foi a que norteou a elaboração da Constituição Federal de 1988 - CF/1988 (BRASIL, 1988) - e a da Lei de Diretrizes e Bases da Educação Nacional de 1996 - LDB/1996 (BRASIL, 1996). A atual Carta Magna, pela primeira vez, na história do Brasil, estabeleceu direitos específicos das crianças, para além daqueles do âmbito da família. Essa postura do legislador fundamentou-se em uma nova concepção de infância, que atribui à criança a condição de cidadã, em período peculiar de seu desenvolvimento como ser humano e que, em decorrência dessa especificidade, sua proteção integral necessita ser assegurada pelo poder público, pela família e pela sociedade, com absoluta prioridade. Essa concepção adotada pela Carta Magna de 1988 foi construída historicamente no interior dos movimentos sociais e dos estudos científicos no campo da infância.

Orientada por esse espírito, a CF/1988 reconheceu, também de maneira inédita na legislação nacional, o direito à educação, desde o nascimento, e o dever do Estado de assegurá-lo. Por sua vez, a LDB/1996 conferiu à educação infantil o status de primeira etapa da educação básica. Com isso, retirou-a do âmbito da assistência e inseriu-a nos sistemas educacionais. Dessa forma, estendeu-se para as creches e pré-escolas os mesmos princípios e garantias das outras etapas e níveis da educação nacional (CORRÊA, 2007).

A CF/1988 e a LDB/1996 sofreram, nos anos que se seguiram à sua aprovação, várias modificações, das quais algumas representam avanços, mas outras ameaçam a concepção construída no bojo dos movimentos sociais. O cumprimento da Meta 1 do PNE 2014-2024 aponta, como um dos primeiros desafios a serem enfrentados, a garantia dessa concepção de educação infantil, construída no Brasil nos últimos trinta anos, a fim de assegurar o direito das crianças de zero a cinco anos de acesso a creches e a pré-escolas de qualidade social, com vistas a superar as desigualdades de classe, gênero e etnia/cor nesse acesso. Para tanto, o PNE 2014-2024 traça como a primeira de suas estratégias:

1.1) definir, em regime de colaboração entre a União, os Estados, o Distrito Federal e os Municípios, metas de expansão das respectivas redes públicas de educação infantil segundo padrão nacional de qualidade, considerando as peculiaridades locais (BRASIL, 2014a).

Cury (2010) aponta como um dos principais entraves na garantia do cumprimento do direito a uma educação de qualidade, desde o nascimento, a ausência de definição do que vem a ser o regime de colaboração determinado pela Constituição Federal e as questões federativas pendentes. De acordo com a CF/1988 e a LDB/1996, a União deveria assumir uma presença articuladora supletiva, técnica e redistributiva, diante do conjunto da educação nacional. Entretanto, esse dever tem sido sistematicamente descumprido, nutrindo, desse modo, as disparidades regionais da federação. 


\section{autêntica}

A União, os estados, o Distrito Federal e os municípios têm o dever de assegurar, em regime de colaboração, o direito à educação desde o nascimento a todos os cidadãos. Entretanto, uma vez que a Lei não definiu claramente como deveria ser o regime de colaboração entre os entes federados, a forma de efetivá-lo ficou sujeita à diversidade de interpretação e a incoerências políticas. Para superar essa situação, é necessária a regulamentação do artigo 23 da Constituição Federal de 1988, que define competências comuns à União, aos estados, ao Distrito Federal e aos municípios, dentre elas, a tarefa de proporcionar os meios de acesso à educação.

O novo PNE, por força da Emenda Constitucional n 59/2009 (BRASIL, 2009a), foi elevado à condição de articulador do Sistema Nacional de Educação (SNE), e a Lei 13.005/2014 (BRASIL, 2014a), que aprovou o Plano Nacional de Educação 2014-2024, no seu art. 13, determina o prazo de dois anos, a partir de sua publicação, para a elaboração da lei específica, que irá instituir o SNE. O desafio atual para a sociedade civil consiste, portanto, em construir os consensos possíveis em torno de temas estruturantes de um modelo de federalismo educacional que atenda às reais necessidades do nosso país.

O Federalismo brasileiro foi conformado pela Constituição Federal de 1988, no contexto histórico das lutas pela redemocratização do país após a ditadura militar, marcado por forte pressão política para a descentralização de poder. Essa tendência fez com que o modelo definido fortalecesse a autonomia dos entes federados, dificultando a criação de uma identidade nacional. Como consequência dessa organização político-administrativa de nosso país, decorrem grandes lacunas nas políticas sociais: "descontinuidade, fragmentação de programas, ausência de padrões de qualidade, ineficiência de órgãos gestores e insuficiência de recursos" (MARQUES, NOGUEIRA, LAMBERTUCCCI, GROSSI, sd., p. 2).

Esse modelo de federalismo foi construído historicamente, no Brasil, como fruto das disputas entre o nacional e o local, permeadas pelos interesses das elites políticas, que remontam ao período imperial. Ele implica sérias questões de distribuição de competências e recursos, que, no campo da educação básica, são agravadas em razão do histórico distanciamento da União no que se refere à oferta desse nível de ensino. A esses fatores políticos associam-se as desigualdades econômicas e sociais, também históricas no Brasil, que ampliam a complexidade e as tensões próprias do nosso contexto federativo.

Nesse cenário complexo, a CF/1988, ao assegurar a educação infantil como direito de todos, define o município como o ente federado que tem o dever de assegurá-lo, em colaboração com estados e a União. 0 atendimento educacional da criança pequena com a necessária qualidade social, porém, demanda gastos que grande parte dos municípios brasileiros, com a atual configuração tributária, sem a colaboração dos estados e da União, não têm condições de assumir.

Assim, é importante salientar que a Carta Magna determinou a atuação prioritária dos municípios na Educação Infantil, em colaboração com os estados e a União, que, no entanto, não foram desresponsabilizados pela assistência técnica e financeira necessárias à sua oferta. Daí a importância, para essa etapa da educação básica, da regulamentação do regime de colaboração.

Para haver uma real ampliação dos gastos públicos com educação no país, é imprescindível o aumento da participação da União no financiamento da educação básica. De acordo com Pinto (2010), embora o governo federal fique com cerca de $60 \%$ da receita tributária líquida - já incluídas as transferências constitucionais para estados e municípios -, sua participação nos gastos com educação básica no período de 2000 a 2005 foi em média de 6\%.

Essa distribuição desigual das receitas tributárias tem sido um dos entraves na ampliação da oferta e da meIhoria da qualidade da educação infantil. Os dados do IBGE (BRASIL, 2014b) demonstram o predomínio dos 
municípios na oferta dessa etapa da educação básica que, em 2013, atingiram 63,2\% em creches e 73,9\% em pré-escolas. Isso confere grande complexidade à organização do atendimento na educação infantil, em decorrência dos diferentes arranjos das políticas municipais e das desigualdades, tanto no que se refere à cobertura da demanda quanto à qualidade do atendimento, no país.

Araújo (2010) avalia que, no cenário atual, é imprescindível assegurar a definição do papel da União na cooperação técnica, na determinação de mecanismos de redistribuição e na garantia de um custo aluno-qualidade (CAQ). Para ela, isso favoreceria o aprofundamento do debate sobre a regulamentação do Sistema Nacional de Educação (SNE). De acordo com a autora, o desafio maior para as relações intergovernamentais no Brasil e para a constituição de um SNE é a definição do regime de colaboração por meio de uma regulamentação que promova uma justa distribuição de poder, autoridade e recursos entre os entes federados, na qual se assegure a independência e a interpenetração dos governos nacional e subnacionais, a fim de possibilitar um projeto de desenvolvimento nacional, que promova a superação das históricas desigualdades regionais e intraestaduais. Para tanto, é fundamental estabelecer uma cooperação vertical que permita alguma incidência na questão do federalismo fiscal, abrindo caminho para o estabelecimento futuro de cooperações mais horizontais entre os entes federados.

Assegurar recursos financeiros é imprescindível para possibilitar a ampliação e a melhoria do atendimento nessa etapa da educação básica, conforme atestam os movimentos sociais e a produção acadêmica na área. Além disso, é essencial o levantamento detalhado da demanda por creche e por pré-escola, a fim de organizar o apoio do estado e da União para a expansão da rede física - reestruturação e aparelhagem da rede - e para a implantação de políticas de formação inicial e continuada, bem como de valorização dos profissionais da educação, tema que será discutido no próximo item.

\section{A FORMAÇÃO E A VALORIZAÇÃO DOS (DAS) PROFISSIONAIS DA EDUCAÇÃO INFANTIL: AVANÇOS E DESAFIOS NA LEGISLAÇÃO, METAS E POLÍTICAS PÚBLICAS EM ANDAMENTO}

A Lei de Diretrizes e Bases da Educação Nacional - Lei 9.394/96 (BRASIL, 1996) -, ao considerar a Educação Infantil como a primeira etapa da Educação Básica, amplia as obrigações do Estado - nas três esferas: municipal, estadual e federal - para com a infância e a demanda pelo estabelecimento de políticas educacionais relacionadas ao seu desenvolvimento, com a previsão de metas, de curto, médio e longo prazos (PEREIRA eTEXEIRA, 1997).

A integração aos sistemas de ensino tem exigido políticas de valorização e de formação do docente que atua com a criança de zero até cinco anos, visto que a qualidade de seu trabalho está diretamente relacionada com sua formação inicial e continuada, bem como a implantação de planos de carreira e salários condizentes com a importância de sua tarefa educativa. Entretanto, conforme regulamenta o artigo 62 da LDB 9.394/96, a formação do professor da educação infantil e dos primeiros anos do ensino fundamental permanece sendo permitida nos cursos normais de nível médio (BRASIL, 1996).

Ao admitir uma formação mínima de nível médio para o exercício do magistério na educação infantil e nos anos iniciais do ensino fundamental, evidencia-se que o legislador preferiu privilegiar as últimas séries da educação básica, em prejuízo da qualidade de sua base, que seriam os anos iniciais, momento em que as crianças precisam de cuidado, atenção e educação de qualidade. Deste modo, perde-se - às vezes de forma irreparável - a oportunidade de contribuir para a sólida formação integral dos cidadãos brasileiros. 


\section{autêntica}

As primeiras das diretrizes curriculares para os cursos de formação de professores regulamentadas pelo governo foram as Diretrizes para a Formação de Docentes da Educação Infantil e anos iniciais do Ensino Fundamental, em nível médio, na modalidade Normal, por meio da Resolução CEB/CNE no 02 de abril de 1999 (BRASIL, 1999). As diretrizes para a formação de professores em nível superior, em cursos de licenciatura plena, só foram homologadas pelo MEC, em fevereiro de 2002, pela Resolução CP/CNE no 1, de fevereiro de 2002 (BRASIL, 2002). As Diretrizes Curriculares Nacionais para o Curso de Pedagogia, por sua vez, só tiveram sua aprovação, posteriormente, por meio da Resolução CNE/CP no $1^{\circ}$ de maio de 2006 (BRASIL, 2006a).

Consideramos que a aprovação das Diretrizes Curriculares para o curso de Pedagogia foi uma conquista para os docentes da educação infantil, na medida em que define esse curso como locus da sua formação, avançando muito em relação à LDB. Conforme Cruz (2010), essas diretrizes abrangem os conhecimentos acumulados na área da educação infantil, ao afirmar que o egresso do curso de Pedagogia deverá estar apto a "[...] compreender, cuidar e educar crianças de zero a cinco anos de forma a contribuir para o seu desenvolvimento nas dimensões, entre outras, física, psicológica, intelectual e social" (BRASIL, 2006a).

Apesar desses avanços, podemos perceber que permanece atual a tendência de perpetuar a formação dos docentes da educação infantil e dos anos iniciais do ensino fundamental em nível médio, na modalidade normal, quando analisamos as alterações inseridas na LDB/1996, pela Lei 12.014 de 6 de agosto de 2009 (BRASIL, 2009b). A partir de então o art. 61 passou a ter a seguinte formulação:

\footnotetext{
Art. 61. Consideram-se profissionais da educação escolar básica os que, nela estando em efetivo exercício e tendo sido formados em cursos reconhecidos, são:

I - professores habilitados em nível médio ou superior para a docência na educação infantil e nos ensinos fundamental e médio (BRASIL, 1996).
}

Treze anos depois de aprovada a LDB, é reafirmada a possibilidade de a formação dos professores da educação infantil e dos anos iniciais do ensino fundamental ser realizada em cursos normais de nível médio. Essa foi uma questão bastante polêmica nas Conferências Nacionais de Educação - CONAE/2010 e CONAE/2014. Os movimentos em defesa da formação dos profissionais da educação preconizam que a formação do professor da educação infantil e dos anos iniciais do ensino fundamental seja feita apenas em curso superior, licenciatura em Pedagogia. Gestores municipais e estaduais, porém, advogam a permanência da formação no nível médio, alegando a carência de profissionais de nível superior para suprir a demanda, especialmente, nas regiões Norte e Nordeste do país. Além disso, permanecem espalhadas pelo país muitas escolas normais, cujos alunos e professores assumem a defesa de sua manutenção como nível inicial da formação docente.

As informações da pesquisa Professores do Brasil (GATTI; BARRETO, 2009) demonstram que, na educação infantil, está a maior incidência de docentes mais jovens, do sexo feminino, não brancas, com escolaridade mais baixa e com menores rendimentos.

Outra recente pesquisa, intitulada Trabalho docente na educação básica no Brasil (OLIVEIRA; VIEIRA, 2010; 2011) evidencia que, na educação de crianças de zero a cinco anos, os salários são inferiores e as jornadas de trabalho diárias e semanais, em um mesmo estabelecimento, são maiores, se comparados às outras etapas da educação básica.

Além disso, observa-se, na realidade nacional, a tendência de uma segmentação entre os que se ocupam das crianças de zero a três anos e os que trabalham com as de quatro a cinco anos e com as turmas dos 


\section{autêntica}

anos iniciais do ensino fundamental. Essa situação é agravada com a tendência da criação de funções e de cargos de trabalho em carreiras paralelas às do magistério público, mais desvalorizadas e precarizadas, sem exigências de formação pedagógica.

De acordo com Vieira (2011), essa realidade foi confirmada nos índices obtidos por meio do Censo Escolar de 2010, que permitem constatar a predominância de docentes do sexo feminino - 97\% são mulheres - na educação infantil. A autora, com base nas mesmas fontes, evidencia as diferenças regionais em relação à formação nas creches e nas pré-escolas: mais professoras com formação de nível superior no Sudeste e na pré-escola $(51,8 \%)$, prevalecendo as que possuem formação de nível médio no Nordeste e na creche $(49,6 \%)$.

A pesquisadora, balizada pela consulta à série histórica das estatísticas divulgadas pelo Inep, afirma que houve alguma mudança na situação da formação das professoras que atuam na educação infantil, pois, desde 2002, vem se ampliando o número de docentes licenciadas em nível de ensino superior e diminuindo as que possuem apenas o ensino fundamental, completo ou incompleto. Isso representa uma relevante conquista, pois a formação do profissional é condição indispensável para uma educação infantil de qualidade. No entanto, os dados disponíveis evidenciam que estamos longe de atingir a meta de $70 \%$ de docentes com formação superior nas creches e pré-escolas, que foi estipulada no PNE 2001-2010 (BRASIL, 2001).

Vieira (2011) defende que o acompanhamento das metas do novo PNE implica a melhoria do acesso a informações quantitativas que permitam a compreensão mais precisa da realidade da formação e do trabalho dos profissionais que atuam na educação da primeira infância no país. A autora afirma que os dados produzidos, atualmente, são divulgados de forma desagregada, não permitindo a apreensão, por exemplo, daqueles referentes aos docentes das instituições particulares, comunitárias, filantrópicas e confessionais nos censos escolares. Além disso, não existe acesso a informações sobre outros profissionais não docentes, que se ocupam de grupos de crianças e executam trabalho similar aos professores, exercendo funções pedagógicas, segundo se pode conhecer por meio de observações e estudos em andamento. Conhecer e transformar a realidade do trabalho desses profissionais se constitui em um relevante desafio que a sociedade brasileira deverá enfrentar no processo de discussão e de elaboração dos planos de carreira, em cumprimento da lei que estabeleceu o piso salarial profissional nacional para os professores (BRASIL, 2008).

Diante desse quadro, defendemos a necessidade de se garantir a todos os trabalhadores que atuam na formação das crianças de zero a cinco anos o seu reconhecimento como docente, pois a natureza do seu trabalho, o espaço institucional onde atuam e a formação requerida são os mesmos daqueles que são considerados professores regentes. Com relação à formação dos diferentes profissionais da educação que atuam em creches e pré-escolas, a estratégia 1.8 estipula:

1.8. promover a formação inicial e continuada dos(as) profissionais da educação infantil, garantindo, progressivamente, o atendimento por profissionais com formação superior (BRASIL, 2014a).

Pode-se perceber que não se faz distinção, nessa estratégia, entre profissionais docentes -regentes ou auxiliares - e não docentes. Apenas se indica que deve ser garantida a ampliação progressiva da sua formação em nível superior.

Apesar dessa realidade, aqui apresentada de maneira sintética, o PNE 2014-2024 ousou propor na Meta 15 que no final da década todos os professores da educação básica deverão ter formação específica de nível superior, obtida em curso na área de conhecimento em que atua. A se referir à educação básica como um 


\section{autêntica}

todo, podemos considerar que a meta estipula que, até 2024, os profissionais do magistério que atuam na educação das crianças de zero a cinco anos, também, tenham conquistado a formação em nível superior, como seus colegas que atuam no ensino fundamental e médio, visto que a educação infantil constitui-se a primeira etapa da educação básica.

O poder público, porém, tem privilegiado programas emergenciais de formação em serviço, com o objetivo de prover a formação inicial de professores que já atuam nos sistemas de ensino, mas que não possuem a formação adequada, ou seja, considerados leigos em seu oficio.

Para atender o que preconiza o Decreto $n^{\circ} 6.755$, de 29 de janeiro de 2009 (BRASIL, 2009c), o Plano Nacional de Formação de Professores da Educação Básica (Parfor) oferta cursos de licenciatura para professores que estão em exercício nas redes públicas de ensino e que não possuem a licenciatura na área. Essa iniciativa, de caráter emergencial, estimula professores da Educação Infantil que só possuem o Curso Técnico de Magistério, o Curso Normal de Nível Médio ou outro curso de licenciatura a cursar Pedagogia.

O Curso de Pedagogia do Parfor é oferecido em período especial, para que o professor/estudante tenha a possibilidade de continuar trabalhando. São ao todo 92 instituições de ensino superior (universidades federais, estaduais, centros universitários, associações e institutos) que ofertam esse curso, totalizando 599 turmas em andamento1. Se tivermos uma média de 40 alunos por turma, serão ao todo 439.600 alunos em formação que estarão aptos a atuar na Educação Infantil, além daqueles formados pela oferta regular e pela Educação a Distância (Ead).

Muitos alunos do Parfor moram em cidades do interior e participam das aulas nas capitais ou outros polos. É uma grande oportunidade para aqueles que não possuem alguma instituição de ensino superior (IES) em seu município. A grande questão é que esses cursos não se consolidam como cursos de oferta regular, ou seja, possuem duração efêmera. Desse modo, os docentes que neles atuam também não tem contrato permanente, mas recebem como bolsistas, em uma nítida precarização das relações de trabalho. Ao término do programa, os cursos são extintos e os professores dispensados.

Outra questão relevante são as dificuldades encontradas pelos professores/alunos para o seu deslocamento, alimentação, hospedagem e, até mesmo, a formação básica precária. Muitos desses docentes/estudantes que frequentam os cursos do Parfor estão atuando nas escolas como alfabetizadores, mas possuem erros graves relacionados à língua portuguesa. A formação superior, muitas vezes, não consegue superar os déficits relacionados à formação básica, considerando que os professores/estudantes possuem pouco tempo para se dedicar aos estudos, visto que não são dispensados de suas atividades profissionais. Por outro lado, podemos encontrar alunos que se destacam pela experiência em sala de aula, com ações pedagógicas criativas, práticas e um discurso claro, porém de embasamento teórico pobre ou inexistente.

Araújo, Silveira e Cotrim (2013) ponderam que, geralmente, nos programas emergenciais de formação de professores, em serviço, o governo e as instituições educativas delegam às professoras a responsabilidade por sua formação, pois não assumem sua tarefa de garantir condições reais para que elas possam conquistar com dignidade seu desenvolvimento profissional. As docentes que frequentam os cursos estudam em horários furtivos às obrigações do trabalho docente e doméstico, visto que são mulheres, em sua maioria, penalizadas por uma jornada dupla ou tripla de trabalho. Desse modo, são privadas do tempo de lazer e descanso. 


\section{autêntica}

Essas condições de formação inicial e continuada reforçam as tendências já tradicionais na educação brasileira com relação às professoras da educação infantil: preconceito, baixos salários, poucas expectativas de profissionalização e baixa identidade profissional (CERISARA, 2002).

As condições de trabalho e a desvalorização da profissão docente têm afastado os jovens da carreira do magistério. As estatísticas demonstram a diminuição da procura por cursos de licenciatura nas instituições formadoras públicas ou particulares (OLIVEIRA et al., 2010).

Diante disso, o governo tem proposto algumas medidas para incentivar a procura e a permanência dos alunos do ensino superior nos cursos de licenciatura como o Programa Institucional de Bolsas de Iniciação à Docência (Pibid). Lançado pela Capes (Coordenação de Aperfeiçoamento de Pessoal do Ensino Superior) em janeiro de 2007, esse Programa é uma iniciativa para o aperfeiçoamento e a valorização da formação de professores para a educação básica. O Pibid foi instituído em 4 de abril de 2013, pela Lei 12.796, com vistas a promover a inserção dos estudantes no contexto das escolas públicas, desde o início da sua formação acadêmica para que desenvolvam atividades didático-pedagógicas sob orientação de um docente da licenciatura e de um professor da escola. São concedidas, ao todo, 72.000 bolsas a alunos dos cursos de Licenciatura, professores de Instituições de Educação Superior (IES) e das escolas das redes públicas. É um programa de grande abrangência que propicia a articulação entre a teoria e prática pedagógica em sala de aula, tão essenciais para atuação na educação infantil. Aqui, a proposta é inversa ao Parfor: o aluno que não tem experiência em docência irá reconhecer a realidade da escola em um processo de formação crítica, necessária para a sua compreensão.

A meta 15 do PNE 2014-2024, na estratégia 15.3, prevê a ampliação do Pibid, o que pode ser considerado uma importante conquista no que se refere ao incentivo à permanência dos estudantes nos cursos de licenciatura e na melhoria da sua qualidade em razão da promoção da relação entre teoria e prática e da aproximação entre as instituições formadoras e os sistemas de ensino, princípios defendidos pelos movimentos em defesa da formação e da valorização dos profissionais da educação.

A Diretoria de Formação de Professores da Educação Básica da Capes, além do Pibid, promove o aperfeiçoamento dos cursos de licenciatura por meio de outros programas, por meio de editais, como o Prodocência (Programa de Consolidação das Licenciaturas), que fornece financiamento para o custeio de atividades voltadas para inovação e qualidade de ensino nos cursos de licenciatura e o Life (Programa de apoio a laboratórios interdisciplinares de formação de educadores), com o financiamento de equipamentos para o desenvolvimento de metodologias, práticas pedagógicas interdisciplinares e fortalecimento das licenciaturas.

O Prodocência tem como finalidade o fomento à inovação e à elevação da qualidade dos cursos de formação para o magistério da Educação Básica, na perspectiva de valorização da carreira docente. Seu último edital foi lançado em abril de 2013 com duração máxima de 24 meses. O programa apoia projetos de caráter institucional, de instituições públicas de ensino superior, nos âmbitos Federal, Estadual e Municipal, que possuam cursos de licenciaturas autorizados, na forma da lei, e em funcionamento. Contudo, próximo ao fim da vigência de seu edital, não há indicação de lançamento de novos editais que deem continuidade ao Programa.

O Programa Life lançou editais em 2012 e 2013, selecionando propostas de criação de laboratórios interdisciplinares de uso comum das licenciaturas, destinados a promover a interação entre diferentes cursos de formação de professores, além da articulação entre os programas da Capes relacionados à Educação Básica. 


\section{autêntica}

O Life tem como objetivos: proporcionar formação de caráter interdisciplinar a estudantes de licenciatura; estimular a articulação entre conhecimentos, práticas e tecnologias educacionais em diferentes cursos de licenciatura; promover o domínio e o uso das novas linguagens e tecnologias da informação e da comunicação nos cursos de formação de docentes; permitir o aprendizado, a socialização e o desenvolvimento coletivo de práticas e metodologias, considerando o conhecimento de diferentes disciplinas; promover a criação de espaço para o desenvolvimento de atividades pedagógicas que envolvam os alunos das escolas públicas de educação básica, os licenciandos e os professores dos programas de formação da IES; promover a valorização dos cursos de licenciatura e de Pedagogia.

Todas essas iniciativas, sob supervisão da Capes, estão sujeitas a normas pré-estabelecidas que podem engessar o processo por não respeitarem as especificações das instituições de ensino superior que efetivamente gerenciam o processo. Para não perder a oportunidade de concorrer e ter acesso à verba de incentivo, as instituições que concorrem aos editais, muitas vezes, enfrentam problemas pontuais como a falta de espaço físico e de funcionários administrativos, como vigilantes e laboratoristas, o que deixa os equipamentos em uma situação de vulnerabilidade.

Os problemas decorrentes da implantação desses programas demonstram a necessidade de uma Política Nacional de Formação dos Profissionais da Educação Básica, que viabilize o atendimento às especificidades do magistério nos seus diferentes níveis, etapas e modalidades. Para isso, são necessárias políticas governamentais empreendidas de forma articulada pelas diferentes esferas de governo, envolvendo instituições formadoras de ensino superior e os sistemas de ensino, para assegurar a valorização dos profissionais, incluindo formação inicial e continuada.

A formação continuada envolve atividades de extensão, grupos de estudos, reuniões pedagógicas, cursos, programas e ações para além da formação mínima exigida ao exercício do magistério na educação básica, tendo como principal finalidade a reflexão sobre a práxis educacional e a busca de aperfeiçoamento técnico, pedagógico, ético e político do profissional docente.

Ela é um requisito fundamental para o desenvolvimento profissional dos professores e deve levar em consideração a realidade educacional nacional com suas diversidades regionais, culturais e sociais, assim como os problemas e os desafios da escola e dos sujeitos que a constroem em seu cotidiano. Deve promover o protagonismo dos docentes e demais profissionais da educação e lhes possibilitar a vivência de tempos e espaços que lhes permita refletir criticamente e aperfeiçoar sua práxis, por meio do diálogo e da parceria com atores e instituições competentes, a fim de alavancar novos patamares de qualidade ao complexo trabalho de gestão da sala de aula e da instituição educativa.

Com esse espírito, a Meta 16 do PNE 2014-2024 estabelece que, no final da década, 50\% dos professores da educação básica devem ter formação em nível de pós-graduação. Essa meta também se refere à formação continuada dos profissionais não docentes que atuam na educação básica, assegurada pela nova redação da LDB/1996.

A fim de promover a formação continuada do professor de educação infantil, prevista na LDB, Araújo; Silveira; Cotrim (2013) defendem a necessidade de assegurar condições de trabalho que possibilitem a realização de estudos, discussões teórico-práticas sobre sua atuação pedagógica, bem como sua participação efetiva, na equipe da instituição educacional, com a responsabilidade de formular, implementar, avaliar e modificar o seu projeto educativo. A qualificação do professor da educação infantil deve possibilitar-lhe refletir teoricamente, 


\section{autêntica}

não apenas acerca do contato direto com a criança, mas também, da construção de sua identidade profissional, superando a histórica descaracterização desse profissional como docente. Acreditamos que é preciso que o docente que atua com crianças pequenas se perceba como um profissional, que possui um objeto de estudo e uma área de atuação definida e com a devida relevância social, a fim de que possa se organizar para exigir melhores condições de formação e de trabalho.

Entretanto, vale perguntar: quem quer ser professor de educação infantil nos dias atuais? Pesquisas evidenciam que a carreira não é atrativa tanto pelo salário quanto pela atividade em si, que muitas vezes torna-se extenuante, com poucas horas dedicadas ao estudo e ao planejamento de ensino. Os egressos do ensino médio, que têm melhores rendimentos, não se sentem atraídos a se tornarem professores e buscam cursos em outras áreas. Para Oliveira et al. (2010, p. 563):

Diferentemente dos países de alto desempenho, o Brasil atrai indivíduos com baixo rendimento acadêmico e com perfil socioeconômico mais baixo para programas de formação de professores. Além do perfil dos que são atraídos para a carreira docente, há que se levar em conta também a qualidade da formação oferecida a esses futuros professores.

Os autores afirmam que: "Não há dúvidas de que para atrair indivíduos mais qualificados para a carreira docente devemos melhorar os incentivos salariais e o status social da profissão" (OLIVEIRA et al., 2010, p.564).

No intuito de superar o desinteresse pela profissão docente, a Meta 17 do PNE 2014-2024 prima pela valorização dos profissionais do magistério das redes públicas de educação básica e propõe a equiparação de seu rendimento ao dos demais profissionais com escolaridade equivalente, até o final do sexto ano de vigência desse Plano.

Hoje, a defasagem entre o salário do professor e dos demais profissionais com ensino superior é de aproximadamente 54\%, conforme dados da Pesquisa Nacional por Amostra a Domicílios (Pnad). Essa diferença é inaceitável, porém, em seis anos, os estados e municípios não terão condições de assumir esse reajuste de forma acelerada, sem a devida ampliação de assistência financeira da União aos entes federados.

A fim de assegurar a valorização dos professores da educação básica, a meta 18 estabelece o prazo de dois anos para que os profissionais da educação básica, incluindo os da Educação Infantil, tenham assegurados seus planos de carreira, tomando como base o piso salarial profissional. Contudo, não há, atualmente, nenhum tipo de punição para o município que alega não possuir condições de pagar esse valor.

Para resolver esse problema, a Meta 20 do PNE, que determina a ampliação do investimento público em educação pública, de forma a atingir, no mínimo 7\% do Produto Interno Bruto (PIB) do país, até 2019, e 10\%, até 2024, estabelece, na estratégia 20.11, que, no prazo de um ano após a aprovação do PNE, seja aprovada a Lei da Responsabilidade Educacional. Com isso, pretende-se assegurar o padrão de qualidade da educação, ao criarem-se mecanismos legais para que cada sistema ou rede de ensino seja responsabilizado pelo cumprimento das metas de qualidade aferidas por institutos oficiais de avaliação educacionais. 


\section{autêntica}

\section{CONSIDERAÇÕES FINAIS}

A despeito dos avanços legais, o panorama brasileiro continua apresentando desigualdades no acesso, na qualidade e na permanência de estudantes, em todos os níveis, etapas e modalidades da educação. Para a efetiva garantia do direito à educação de qualidade social, fazem-se necessárias políticas públicas, que visem à superação do cenário. Para tanto, é necessária a construção do Sistema Nacional de Educação (SNE) como política de Estado consolidada na organicidade entre os processos, na organização, na regulação, na fiscalização, na ação sistêmica e no financiamento. O PNE, com seus princípios, metas e estratégias, constitui-se, hoje, em um importante articulador do SNE e demanda um esforço conjunto dos entes federados no cumprimento das metas estabelecidas.

No que se refere à educação infantil, o grande desafio das políticas para quitar a dívida que vem se acumulando historicamente, no que se refere à educação das crianças pequenas no país, é investir fortemente na expansão da oferta para a universalização da matrícula das crianças de quatro a cinco anos na pré-escola, assegurando a qualidade do seu atendimento, sem que isso represente o abandono das menores por parte do poder público. Embora a meta de expansão do atendimento em creches tenha se mantido a mesma do PNE 2001-2010, será necessário um esforço articulado das três esferas para atingi-la e para ampliá-la, a fim de assegurar o direito à creche, previsto na Constituição Federal de 1988, para todas as crianças das famílias que o demandarem.

Assegurar a educação infantil com qualidade, como direito de todas as crianças, é tarefa do município, em colaboração com estados e a União, pois requer investimentos, que grande parte dos municípios brasileiros não tem condições de assumir sem a colaboração dos estados e da União. Assim, para assegurá-la é fundamental a definição do regime de colaboração determinado pela Constituição Federal e das questões federativas pendentes, a fim de que a União assuma sua função articuladora supletiva, técnica e redistributiva, diante do conjunto da educação nacional, pois, só com a real ampliação dos gastos públicos na educação e com o aumento da participação da União no financiamento da educação básica, será possível cumprir as metas estabelecidas no novo PNE.

As metas de expansão da educação infantil, por meio da universalização da pré-escola e do atendimento de no mínimo $50 \%$ das crianças de zero a três anos até 2024, implicam a necessidade de suprir a carência de professores na área. Por outro lado, é fundamental assegurar a esses professores formação inicial e continuada, salários, condições de trabalho e carreiras dignas, integradas ao magistério da educação básica, rompendo com as dicotomias entre professores regentes e auxiliares, atividades de cuidado e educativas.

Os movimentos sociais em defesa da educação pública de qualidade social e da formação e da valorização dos profissionais da educação precisam estar atentos e coesos na exigência do cumprimento das metas e estratégias do PNE 2014-2024, que, embora tenham sido aprovadas por lei federal, só se efetivarão, na realidade social e educacional, se a sociedade civil permanecer vigilante e articulada em sua defesa. 


\section{autêntica}

\section{REFERÊNCIAS}

ARAÚJO, Denise Silva; SILVEIRA, Jennifer Martins; COTRIM, Nevione. Políticas Públicas para a Educação Infantil. In:TARTUCI, Dulcéria; FLORES, Maria Marta Lopes (Orgs.). Práticas Educativas e Políticas de Educação Básica. Goiânia: FUNAPE/DEPECAD, 2013, p. 145-165.

ARAÚJO, Gilda Cardoso de. Constituição, federação e propostas para o novo Plano Nacional de Educação: análise das propostas de organização nacional da educação brasileira a partir do Regime de Colaboração. Educ. Soc., Campinas, v.31, no.112, p. 749-768, jul./set., 2010.

BRASIL. Lei n 13.003, de 25 de junho de 2014. Aprova o Plano Nacional de Educação - PNE e dá outras providências. Diário Oficial da União, Brasília, DF, 26 jun. 2014.

BRASIL. Censo Escolar da Educação Básica 2013: resumo técnico. Brasília, DF: IBGE, 2013.

BRASIL. Projeto de Lei do Plano Nacional de Educação (PNE 2011/2020): projeto em tramitação no Congresso Nacional / PL no 8.035 / 2010. Organização: Márcia Abreu e Marcos Cordiolli. Brasília, DF: Câmara dos Deputados, Edições Câmara, 2011.

BRASIL. Constituição (1988). Emenda Constitucional n 59, de 11 de novembro de 2009. Acrescenta $\S 3^{\circ}$ ao art. 76 do Ato das Disposições Constitucionais Transitórias para reduzir, anualmente, a partir do exercício de 2009, o percentual da Desvinculação das Receitas da União incidente sobre os recursos destinados à manutenção e desenvolvimento do ensino, de que trata o art. 212 da Constituição Federal, dá nova redação aos incisos I e VII do art. 208, de forma a prever a obrigatoriedade do ensino de quatro a dezessete anos e ampliar a abrangência dos programas suplementares para todas as etapas da educação básica, e dá nova redação ao $\S 4^{\circ}$ do art. 211 e ao $\S 3^{\circ}$ do art. 212 e ao caput do art. 214, com a inserção neste dispositivo de inciso VI. Diário Oficial da União, Brasília, DF, 11 nov. 2009a.

BRASIL. Lei n 12.014 de 6 de agosto de 2009. Altera o art. 61 da Lei no 9.394, de 20 de dezembro de 1996 , com a finalidade de discriminar as categorias de trabalhadores que se devem considerar profissionais da educação. Diário Oficial da União, Brasília, DF, 7 ago., $2009 b$.

BRASIL. Decreto $n^{\circ}$ 6.755, de 29 de janeiro de 2009. Institui a Política Nacional de Formação de Profissionais do Magistério da Educação Básica, disciplina a atuação da Coordenação de Aperfeiçoamento de Pessoal de Nível Superior - CAPES no fomento a programas de formação inicial e continuada, e dá outras providências. Diário Oficial da União, Brasília, DF, 30 jan. 2009c.

BRASIL. Lei $n^{\circ}$ 11.738, de 16 de julho de 2008. Regulamenta a alínea "e" do inciso III do caput do art. 60 do Ato das Disposições Constitucionais Transitórias, para instituir o piso salarial profissional nacional para os profissionais do magistério público da educação básica. Diário Oficial da União, Brasília, DF, 17 jul. 2008.

BRASIL. Resolução CNE/CP n 1, de 15 de maio de 2006. Institui Diretrizes Curriculares Nacionais para o Curso de Graduação em Pedagogia, licenciatura. Diário Oficial da União, Brasília, DF, Ministério da Educação. Conselho Nacional de Educação, 16 maio 2006a. 


\section{autêntica}

BRASIL. Lei n 11.274, de 6 de fevereiro de 2006. Altera a redação dos arts. 29, 30, 32 e 87 da Lei no 9.394, de 20 de dezembro de 1996, que estabelece as diretrizes e bases da educação nacional, dispondo sobre a duração de 9 (nove) anos para o ensino fundamental, com matrícula obrigatória a partir dos 6 (seis) anos de idade. Diário Oficial da União, Brasília, DF, 7 fevereiro 2006b.BRASIL. Resolução CNE/CP n¹, de 18 de fevereiro de 2002, que institui Diretrizes Curriculares Nacionais para a Formação de Professores da Educação Básica, em nível superior, curso de licenciatura, de graduação plena. Diário Oficial da União, Brasília, DF, 19 fevereiro 2002.

BRASIL. Lei n 10.172, de 9 de janeiro de 2001. Aprova o Plano Nacional de Educação e dá outras providências. Diário Oficial da União, Brasília, DF, 10 jan. 2001.

BRASIL. Resolução CNE/CEB, n² 2, de 19 de abril de 1999. Institui Diretrizes Curriculares Nacionais para a Formação de Docentes da Educação Infantil e dos anos iniciais do Ensino Fundamental, em nível médio, na modalidade Normal. Diário Oficial da União, Brasília, DF, 2 abril 1999.

BRASIL. Lei n 9.394, de 20 de dezembro de 1996. Estabelece as diretrizes e bases da educação nacional. Diário Oficial da União, Brasília, DF, 23 dez. 1996.

BRASIL. Constituição (1988). Constituição da República Federativa do Brasil. Brasília: Senado Federal, 1988.

CERISARA, Ana Beatriz. Professoras de educação infantil: entre o feminino e o profissional. São Paulo: Cortez, 2002.

CORRÊA, Bianca Cristina. A educação infantil. In: OLIVERIA, Romualdo Portela de e ADRIÃO, Thereza (Orgs.) Organização do Ensino no Brasil: níveis e modalidades. 2 ed. São Paulo: Xamã, 2007. p. 13-30.

CURY, Carlos Roberto Jamil. A questão federativa e a educação escolar. In: OLIVEIRA, R.P.; SANTANA, W. (Orgs.). Educação e Federalismo no Brasil: combater as desigualdades, garantir a diversidade. Brasília, DF: UNESCO, 2010. p. 149-168.

FREIRE, Paulo. Pedagogia da indignação: cartas pedagógicas e outros escritos. São Paulo: UNESP, 2000. Disponível em: <http://www.capes.gov.br/educacao-basica/parfor>. Acesso em: 28 maio 2015.

CRUZ, Sílvia Helena Vieira. A formação inicial e continuada e a profissionalidade específica dos docentes que atuam na educação infantil. In: FRADE, Isabel Cristina A. da Silva et al. Convergências e tensões no campo da formação e do trabalho docente. Belo Horizonte: Autêntica, 2010. (Didática e Prática de ensino). p. 351-369.

GANZELI, Pedro. Plano Nacional de Educação: Implicações para s Educação Infantil Revista Exitus, Volume 02, nº 02, p. 77-102, Jul./Dez. 2012.

GATTI, Bernardete Angelina; BARRETO, Elba Siqueira de Sá (Coords.). Professores do Brasil: impasses e desafios. Brasília: UNESCO, 2009.

MARQUES, Binho et al. O Sistema Nacional de Educação: em busca de consensos. sd. Disponível em: <http:// conae2014.mec.gov.br/images/pdf/marques_nogueira_lambertucci_grossi.pdf>. Acesso em: 29 mar 2015. 


\section{autêntica}

OLIVEIRA, Dalila A.; VIEIRA, Lívia M. F. Trabalho docente na educação básica no Brasil. Belo Horizonte: GESTRADO/UFMG, 2010. 80 p. (Relatório de Pesquisa).

OLIVEIRA, Dalila A.; VIEIRA, Lívia M. F. Os sujeitos docentes da educação infantil: formação, carreira e condições de trabalho. Belo Horizonte: GESTRADO/UFMG, 2011. 30 p. (Relatório de Pesquisa).

PEREIRA, Eva Waisros e TEXEIRA, Z. de A. A educação básica redimensionada. In: BRZEZINSKI, I. (Org.). LDB Interpretada: diversos olhares se entrecruzam. São Paulo: Cortez, 1997.

OLIVEIRA, Romualdo Portela et al. Quem quer ser professor? Atratividade, seleção e formação docente no Brasil. Est. Aval. Educ., São Paulo, v. 21, n. 47, p. 543-568, set./dez. 2010.

PINTO, José Marcelino de Rezende. Limites do Pacto Federativo no Financiamento da Educação Básica. Revista da Associação dos Docentes da USP (ADUSP). São Paulo. Janeiro de 2010, n. 46, p. 60-64.

VIEIRA Lívia Maria Fraga. Obrigatoriedade escolar na educação infantil. Revista Retratos da Escola, Brasília, v. 5, n. 9, p. 245-262, jul./dez. 2011. Disponível em: <http//www.esforce.org.br>. Acesso em: 28 mar 2015

VIEIRA Lívia Maria Fraga. A educação infantil e o Plano Nacional de Educação: as propostas da CONAE 2010. Educação \& Sociedade, Campinas, v. 31, n. 112, p. 809-831, jul./set. 2010. 